\title{
๖Microphysics of Convective and Stratiform Precipitation during the Summer Monsoon Season over the Yangtze-Huaihe River Valley, China
}

\author{
Fenguiao Chen, ${ }^{\mathrm{a}, \mathrm{b}}$ Xiaoyi Zheng, ${ }^{\mathrm{c}}$ Huayang Wen, ${ }^{\mathrm{a}}$ And Ye Yuan ${ }^{\mathrm{c}}$ \\ ${ }^{\text {a }}$ Anhui Meteorological Information Centre, Anhui Meteorological Bureau, Hefei, China \\ ${ }^{\mathrm{b}}$ Anhui Province Key Laboratory of Atmospheric Science and Satellite Remote Sensing, Institute of Meteorological Sciences, Hefei, China \\ ${ }^{\mathrm{c}}$ Anhui Province Weather Modification Office, Hefei, China
}

(Manuscript received 15 April 2021, in final form 15 November 2021)

\begin{abstract}
Precipitation microphysics are critical for precipitation estimation and forecasting in numerical models. Using six years of observations from the Global Precipitation Measurement satellite, the spatial characteristics of precipitation microphysics are examined during the summer monsoon season over the Yangtze-Huaihe River valley. The results indicate that the heaviest convective rainfall is located mainly between the Huaihe and Yangtze Rivers, associated with a smaller mass-weighted mean diameter $\left(D_{m}=\sim 1.65 \mathrm{~mm}\right)$ and a larger mean generalized intercept parameter $\left(N_{w}\right)$ $\left(\sim 41 \mathrm{~dB} N_{w}\right)$ at $2 \mathrm{~km}$ in altitude than those over the surrounding regions. Further, the convection in this region also has the lowest polarization-corrected temperature at $89 \mathrm{GHz}($ PCT89 < 254 K), indicating high concentrations of ice hydrometeors. For a given rainfall intensity, stratiform precipitation is characterized by a smaller mean $D_{m}$ than convective precipitation. Below $4.5 \mathrm{~km}$ in altitude, the vertical slope of medium reflectivity factor varies with the rainfall intensity, which decreases slightly downward for light rain $\left(<2.5 \mathrm{~mm} \mathrm{~h}^{-1}\right)$, increases slightly for moderate rain $\left(2.5-7.9 \mathrm{~mm} \mathrm{~h}^{-1}\right)$, and increases more sharply for heavy rain $\left(\geq 8 \mathrm{~mm} \mathrm{~h}^{-1}\right)$ for both convective and stratiform precipitation. The increase in the amplitude of heavy rain for stratiform precipitation is much higher than that for convective precipitation, probably due to more efficient growth by warm rain processes. The PCT89 values have a greater potential to inform the near-surface microphysical parameters in convective precipitation compared with stratiform precipitation.
\end{abstract}

KEYWORDS: Precipitation; Satellite observations

\section{Introduction}

Raindrop size distribution (DSD), which is an important microphysical property of precipitation, is affected by physical processes, including breakup, collision-coalescence, evaporation, and size sorting (Kumjian et al. 2014; Rosenfeld and Ulbrich 2003). The knowledge of the characteristics of DSDs is essential for quantitative precipitation estimation (Huang et al. 2020a,b, 2018) and microphysics parameterization in numerical models (Wood et al. 2009).

Using ground-based polarimetric radars and in situ measurements (i.e., disdrometers), it is found that of DSDs for convective and stratiform precipitation can vary in different precipitation types, climatic regions, rainfall events, seasons, and also with topography (Chen et al. 2017; Seela et al. 2018; Tang et al. 2014; Wang et al. 2019; Wen et al. 2019, 2016). For example, Tang et al. (2014) revealed that the convective precipitation over northern China and southern China has a higher mass-weighted mean diameter $\left(D_{m}\right)$ and normalized intercept parameter $\left(N_{w}\right)$ than stratiform precipitation using observations from PARSIVEL disdrometers. Observations from a ground-based two-dimensional video disdrometer (2DVD) and a vertically pointing Micro Rain Radar (MRR) have been used to reveal that the DSDs of monsoon

¿ Denotes content that is immediately available upon publication as open access.

Corresponding author: Ye Yuan, yuanyee2020@163.com precipitation in East China show higher raindrop concentrations and smaller mean diameters than those over the other regions in Asia, which could be attributed to the higher local aerosol concentrations (Wen et al. 2016). DSDs of convective precipitation vary in different monsoon periods (Chakravarty and Raj 2013; Wen et al. 2019), with the $D_{m}$ value being the smallest (largest) in the premonsoon (postmonsoon) period over South China Sea, probably attributed to the differences in warm and cold rain processes, raindrop evaporation, convective activities, and other meteorological factors (Zeng et al. 2019). The DSDs of tropical cyclones exhibit seasonal variations with more large drops in southwest monsoon than in northeast monsoon (Radhakrishna and Narayana Rao 2010). Compared to nontropical cyclones, the DSDs of tropical cyclones are characterized by larger concentrations of small to moderate drop sizes, and fewer large drops (Deo and Walsh 2016; Radhakrishna and Narayana Rao 2010). The terrain features also affect precipitation microphysics (Seela et al. 2017). It is found that $D_{m}\left(N_{w}\right)$ over the Tibetan Plateau is smaller (larger) than that over South China (He et al. 2021).

It is considered that the in situ DSD measurements by disdrometers are generally more accurate than the estimates from the remote sensing data. However, the spatial distribution of disdrometers is usually sparse and not uniform, and it is also not easy to calibrate multiple disdrometers to a consistent level. These factors make it difficult to study spatial patterns of DSDs using disdrometer observations. Although the spatial coverage of polarimetric radars is generally wide, the measurements from polarimetric radars are subject to beam broadening effects and may have a relatively poor vertical 
sampling resolution at large distances from the radars. The latest Dual-Frequency Precipitation Radar (DPR) on board the Global Precipitation Measurement (GPM) satellite (launched in 2014) consists of radars at $\mathrm{Ku}$ and $\mathrm{Ka}$ band, known as the KuPR and KaPR (Hou et al. 2014). The simultaneous observations by the KuPR and KaPR enable the retrieval of DSDs (Le and Chandresekar 2012). Furthermore, the scan swath of DPR is approximately $245 \mathrm{~km}$, and the vertical sampling resolution of DPR has been improved to $125 \mathrm{~m}$, which allows us to study the spatial characteristics of DSDs. Using observations from GPM DPR, recent studies have discovered that the coalescence of rain hydrometeors below the melting layer is the dominant process for precipitating clouds at high precipitation efficiencies within tropical cyclone systems (Chen et al. 2019; Huang and Chen 2019). In the stratiform regions of mei-yu precipitation systems, the coalescence slightly overwhelms the breakup and/or evaporation processes, while it is dominant in the convective regions (Sun et al. 2020).

The brightness temperature from satellite microwave radiometers has been widely used to provide surface rainfall estimates, due to its sensitivity to the scattering or emission of ice-phase or liquid-phase particles within clouds. The $85-\mathrm{GHz}$ brightness temperature obtained by the Tropical Rainfall Measurement Mission (TRMM) satellite is primarily used to estimate rainfall over land (the 2A12 rainfall products), on the basis of empirically derived brightness-temperature-rain-rate relationships (Gopalan et al. 2010). The microwave imager on board the GPM satellite (GMI) and the DPR make it possible to obtain simultaneous measurements of brightness temperature and DSDs. Understanding the relationship between precipitation microphysics and brightness temperature may help improve rainfall estimates from satellites in the future.

The summer precipitation in the Yangtze-Huaihe River valley $\left(27^{\circ}-36^{\circ} \mathrm{N}, 110^{\circ}-122.5^{\circ} \mathrm{E}\right)$ is mainly influenced by the East Asian monsoon. Due to the potential flash floods and landslides caused by persistent heavy rainfall, the precipitation has long been the focus of numerous studies (Ding et al. 2021). Also, studying the characteristics of precipitation at different intensities is essential for an understanding of the responses of precipitation to climate change (i.e., aerosol conditions or air temperatures) and topography in this region (Ding 1994; Ding et al. 2008). However, the statistical knowledge of the microphysics of convective and stratiform precipitation at different rainfall intensities over the Yangtze-Huaihe River valley has been rarely studied. The present study aims to 1) reveal the statistical characteristics of convective and stratiform precipitation microphysics in the summer monsoon season (June-August) between 2014 and 2019, with a special focus on the microphysics of precipitation at different intensities (light, moderate, and heavy), and 2) understand whether brightness temperature from satellite images can be used to infer microphysical structures in this region.

\section{Data and methods}

GPM is an international mission that provides the nextgeneration quasi-global (extending from $65^{\circ} \mathrm{S}$ to $65^{\circ} \mathrm{N}$ ) measurements of precipitation (Iguchi et al. 2002). The Core Observatory satellite carries a DPR operating at the $\mathrm{Ku}$ and $\mathrm{Ka}$ band and a multichannel GMI. Six years (2014-19) of the official level-2 DPR dataset (version 6) and the level-1 GMI/1C dataset (version 5) are used in this study (Iguchi et al. 2017).

The DPR provides rainfall observations at snapshots in time at a 5-km spatial resolution (at nadir) and a $125-\mathrm{m}$ vertical resolution. In the official level-2 DPR dataset, three-dimensional DSD parameters are retrieved based on the measurements of radar reflectivity factors at $\mathrm{Ku}$ and $\mathrm{Ka}$ bands, including the massweighted mean diameter $D_{m}$ (in $\mathrm{mm}$ ) and the generalized intercept parameter $\left(N_{w} ; \mathrm{mm}^{-1} \mathrm{~m}^{-3}\right)$. In the retrieval algorithm, the normalized gamma distribution with the shape parameter $\mu=3$ is assumed (Iguchi et al. 2017). Note that for nonliquid hydrometeors, the liquid-equivalent DSDs are retrieved with a noncoalescence and nonbreakup model assumed for the melting process (Seto and Iguchi 2011). The details of DSD retrievals can be revisited in the algorithm document of the official product (Iguchi et al. 2018) and the work by Chen et al. (2019). Note that $N_{w}$ is shown in the decibel scale $\left(\mathrm{dB} N_{w}\right)$ for convenience in this study. Recent studies have validated the accuracy the DSD retrievals from GPM, which indicated the great potential of DPR-derived DSD parameters in studying microphysical characteristics of precipitation (Huang et al. 2021; Radhakrishna et al. 2016; Sun et al. 2020).

In addition to the DSD parameters, the DPR official dataset also offers the three-dimensional radar reflectivity factor ( $Z_{e}$ : at $\mathrm{Ku}$ band), the near-surface rain rate $(\mathrm{RR})$, and rain type (convective, stratiform, or other) at each DPR scan pixel. In the rain type classification, we mainly adopt the results from the single-frequency (SF) method by jointly examining the vertical profiles (V method) and the horizontal profiles ( $\mathrm{H}$ method) (Awaka et al. 1997). In the V method, convective and stratiform types are classified by considering the existence of bright bands, the value of reflectivity factor, and slope of reflectivity factor profile above the $0^{\circ} \mathrm{C}$ isotherm. In the $\mathrm{H}$ method, the horizontal texture of maximum reflectivity factor corrected for attenuation by nonprecipitation particles $\left(Z_{\max }\right)$ is checked, that is, a pixel is classified as convective if its $Z_{\text {max }}$ exceeds a convective threshold (40 dBZ) or stands out against that in the nearby area (Steiner et al. 1995). Storm-top height (STH) is calculated using the maximum height where the radar reflectivity exceeding $20 \mathrm{dBZ}$ (Chen et al. 2016; Liu et al. 2007). Note that the profiles with STHs more than $1 \mathrm{~km}$ lower than the height of $0^{\circ} \mathrm{C}$, known as shallow convection characterized by pure warm rain processes, are omitted in this study. Further detailed information about the retrieval methods can be revisited in the previous studies (Awaka et al. 2016; Chen et al. 2019; Huang and Chen 2019; Jun et al. 2016; Le and Chandresekar 2012; Smith et al. 2007). According to the weather forecast standard, the rainfall intensity is divided into three grades according to the near-surface RR: light rain $\left(<2.5 \mathrm{~mm} \mathrm{~h}^{-1}\right)$, moderate rain $\left(2.5-7.9 \mathrm{~mm} \mathrm{~h}^{-1}\right)$, and heavy rain $\left(>8.0 \mathrm{~mm} \mathrm{~h}^{-1}\right)$ (Chen and Fu 2015).

The GMI instrument is a conical-scanning multichannel microwave radiometer covering a swath of $885 \mathrm{~km}$ with thirteen channels (Draper et al. 2015). Its beamwidth varies with the channels, which is 4.3 (7.3) $\mathrm{km}$ on the Earth's surface in the along-scan (cross-scan) direction for the 89-GHz channel. 

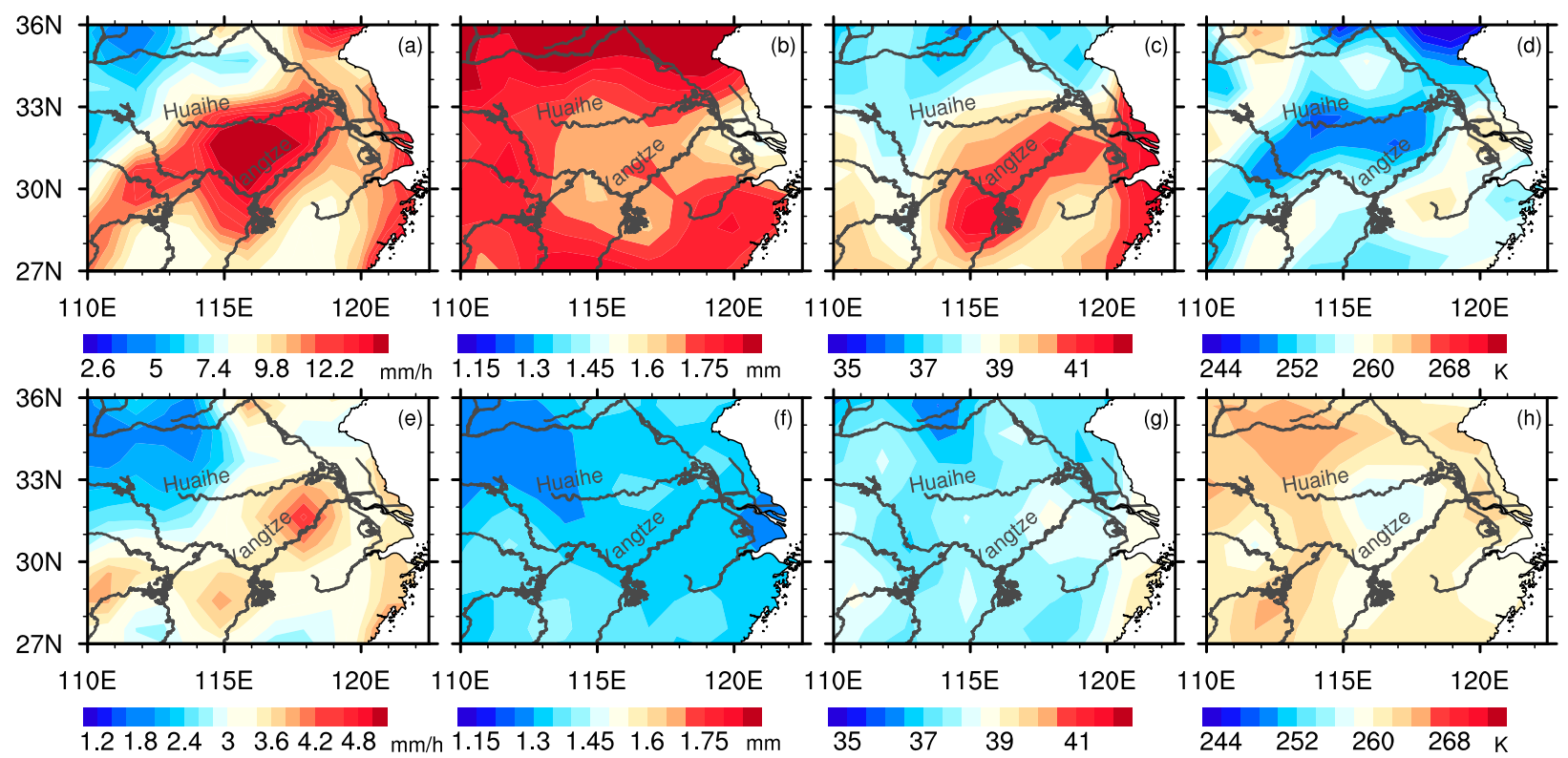

$1.21 .82 .43 \quad 3.64 .24 .8 \mathrm{~mm} / \mathrm{h} 1.151 .31 .451 .61 .75 \mathrm{~mm}$

35

41

(h) PCT89 for (top) convective and (bottom) stratiform precipitation over the Yangtze-Huaihe River valley, China, at $1^{\circ} \times 1^{\circ}$ spatial resolution during the summer monsoon seasons of 2014-19. The solid gray lines indicate the rivers across China, and the locations of the Huaihe and Yangtze Rivers are specifically labeled.

Polarization-corrected temperature for $89 \mathrm{GHz}$ (PCT89) is defined as $1.818 \times T_{89 \mathrm{~V}}-0.818 \times T_{89 \mathrm{H}}$, in which the subscripts $V$ and $H$ indicate vertical and horizontal polarizations, respectively (Spencer et al. 1989). Generally, scattering by large graupel or hail particles within clouds corresponds to a low PCT89 value (Cecil 2009). Since the GMI and DPR have different scan patterns, a simple nearest-neighbor method is implemented when collocating the GMI pixels (PCT89 values) to the DPR pixels. Note that a parallax correction method was implemented by Liu et al. (2008) when collocating the measurements of the Microwave Imager (TMI) and Precipitation Radar (PR) on board the TRMM satellite, which corrects the difference in the view angles of these two instruments. However, this method is optimized for deep convective clouds, which is not suited for the storms with lower echo top. Therefore, it is not adopted in our study considering our purpose is to investigate the characteristics of precipitation of different intensities (light, moderate, and heavy) rather than that of deep convective clouds only.

To investigate the connection of microphysical characteristics with environmental conditions during the summer season, the mean horizontal water vapor flux (WVF) and water vapor flux divergence (WVFD) at $850 \mathrm{hPa}$ are analyzed using the daily ECMWF interim reanalysis (ERA-Interim) dataset. The WVF and WVFD are calculated as follows:

$$
\begin{aligned}
\mathbf{W V F} & =\mathbf{V} q / g, \\
\mathbf{W V F D} & =\nabla \cdot(\mathbf{V} q / g),
\end{aligned}
$$

where $q$ is specific humidity, $g$ is gravitational acceleration $\left(=9.8 \mathrm{~g} \mathrm{~m}^{-2}\right)$, and $\mathbf{V}$ is the horizonal wind.

\section{Results}

\section{a. General patterns}

The mean spatial patterns of near-surface RR, $D_{m}, N_{w}$, and PCT89 for convective and stratiform precipitation are presented in Fig. 1. To guarantee sufficient samples in each gridbox, these mean values are calculated at $1^{\circ} \times 1^{\circ}$ resolution using the ratio of the totals to the total sample during the study period. The mean horizontal patterns of WVF and WVFD at $850 \mathrm{hPa}$ are also demonstrated in Fig. 2 to understand the potential environmental conditions for the differences in spatial patterns. Consistent with many previous studies (e.g., Fu et al. 2016; Yang et al. 2019), the mean RR of convective precipitation is much higher than that of stratiform precipitation, ranging from 5 to $16 \mathrm{~mm} \mathrm{~h}^{-1}$, while it is concentrated between only 1.2 and $4.8 \mathrm{~mm} \mathrm{~h}^{-1}$ for stratiform precipitation. The center of the maximum convective RR is located mainly between the Huaihe and Yangtze Rivers, where the corresponding PCT89 values are generally lower than $252 \mathrm{~K}$ (Fig. 1d). The stratiform RR over this region is also slightly higher than that over the surrounding regions. The heavier rainfall of convective and stratiform precipitation over this region could cause devastating flooding events ( $\mathrm{Yu}$ et al. 2009). Over the northwestern regions of the Yangtze-Huaihe River valley, the convective and stratiform RRs are generally much lower than those of other regions, corresponding well to the relatively higher PCT89 values. The centers of high and low rain fall fit well with the convergence and divergence of moisture at $850 \mathrm{hPa}$, respectively (Fig. 2b). In comparison with stratiform precipitation, the convective precipitating clouds generally exhibit lower PCT89 values than stratiform precipitating clouds. This indicates the growth of larger 

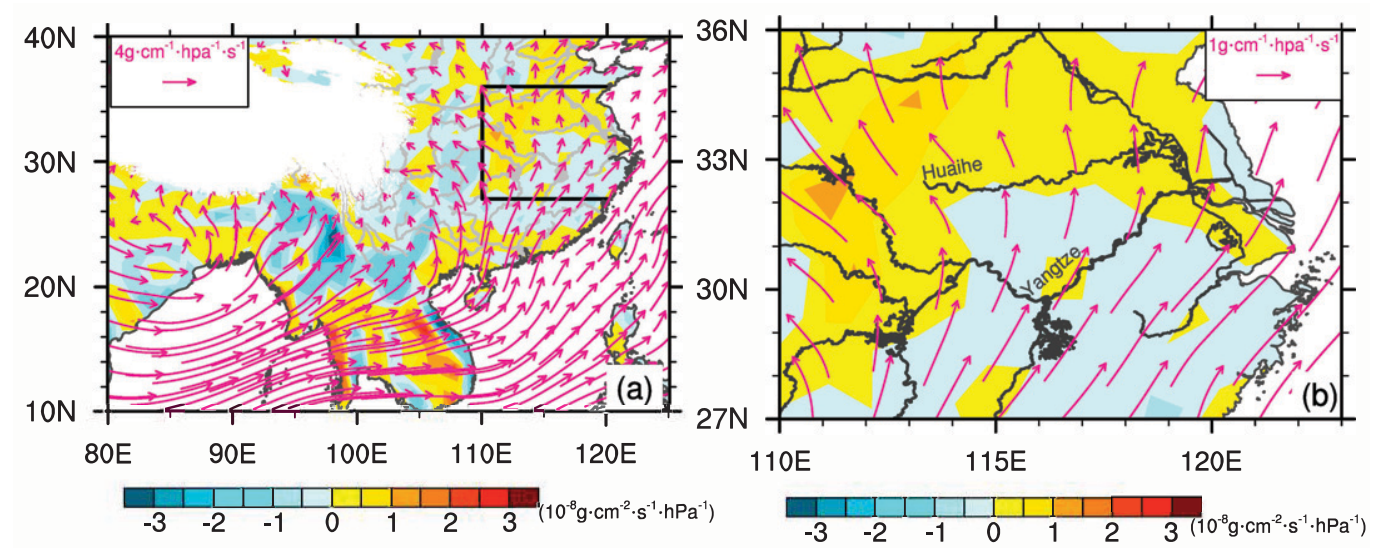

FIG. 2. The mean horizontal patterns of WVF (vectors) and WVFD (shaded) at $850 \mathrm{hPa}$ at $0.5^{\circ} \times 0.5^{\circ}$ spatial resolution during the summer monsoon seasons of 2014-19 (a) over East Asia and (b) over the Yangtze-Huaihe River valley. The black-colored frames in (a) denote Yangtze-Huaihe River valley. The white-shaded regions in (a) indicate the regions with topography higher than $3 \mathrm{~km}$.

amounts of ice hydrometeors due to the strong updraft within convective precipitation. Although the emission of supercooled liquid drops lofted by the updraft (Homeyer and Kumjian 2015; Kumjian et al. 2014) may counteract the PCT89 depression, a sufficient optical depth of ice above the liquid water may negate any radiative effects of the liquid water (Cecil and Zipser 2002).

From the perspective of microphysical characteristics, the mean low-level $D_{m}$ and $N_{w}$ values of convective precipitation (Figs. 1b,c) are much higher than those of stratiform precipitation (Figs. 1f,g), consistent with the findings over northern China and southern China (Tang et al. 2014). For stratiform precipitating clouds, the mean $D_{m}$ and $N_{w}$ (Figs. 1f,g) generally show more uniform spatial distributions. The smallest mean raindrop sizes $\left(D_{m}=\sim 1.25 \mathrm{~mm}\right)$ occur over the northwestern parts of the Yangtze-Huaihe River valley, where the RRs are also low $\left(\sim 2.2 \mathrm{~mm} \mathrm{~h}^{-1}\right)$. These spatial differences in the DSDs may reflect different microphysical processes. It is also shown that the convective precipitating clouds over the northern parts of the Yangtze-Huaihe River valley (approximately at the $35^{\circ}-36^{\circ} \mathrm{N}$ zonal belt) have large mean raindrop sizes $\left(D_{m}>1.8 \mathrm{~mm}\right)$ and small concentrations $\left(\sim 37 \mathrm{~dB} N_{w}\right)$. In comparison, the DSDs over the regions between the Yangtze and Huaihe Rivers (where the convective RR is the highest) have smaller $D_{m}$ and larger $N_{w}$ values $\left(>41 \mathrm{~dB} N_{w}\right)$ than the surrounding regions. Affected by the East Asia summer monsoon, sufficient humid and warm air is transported from the Arabian Sea and Bay of Bengal to the Yangtze-Huaihe River valley in summer (Fig. 2a). As shown in Fig. 2b, the moisture mainly converges over the southern part of the Yangtze-Huaihe River valley, while it diverges over the northern regions. The high precipitation center (shown in Figs. 1a,e) corresponds well the moisture convergence (Fig. 2b) at low levels. Furthermore, there are generally high concentrations of aerosols in East China due to the rapid industrialization (Fu et al. 2016). In the condition of high aerosol loadings and sufficient moisture, abundant cloud condensation nuclei are formed (Liu et al. 2011; Wen et al. 2016), which could probably lead to relatively high concentrations of smallsized raindrops (small $D_{m}$ and high $N_{w}$ values) in the regions between the Yangtze River and the Huaihe River.

\section{b. Precipitation at different rainfall intensities}

In this section, we will further compare the microphysical characteristics of light, moderate, and heavy rain for convective and stratiform precipitation. The mean values and probability distribution functions (PDFs) of the $D_{m}$ and $N_{w}$ at $2 \mathrm{~km}$ in altitude above mean sea level, PCT89 and STH for convective and stratiform precipitation are displayed in Table 1 and Fig. 3, respectively. As indicated by the PDFs of the PCT89 (Figs. 3a,e), the convective and stratiform clouds with higher RR generally have more fractions of lower PCT89 values, which proves larger amounts of ice hydrometeors. The mean PCT89 values of heavy rain are the lowest, compared to those

TABLE 1 . The mean $D_{m}$ and $N_{w}$ at $2 \mathrm{~km} \mathrm{MSL} \mathrm{in,} \mathrm{STH} \mathrm{and} \mathrm{PCT89} \mathrm{for} \mathrm{convective} \mathrm{and} \mathrm{stratiform} \mathrm{precipitation} \mathrm{over} \mathrm{the}$ Yangtze-Huaihe River valley, China, during the summer monsoon seasons of 2014-19.

\begin{tabular}{|c|c|c|c|c|c|c|c|c|}
\hline & \multicolumn{4}{|c|}{ Convective } & \multicolumn{4}{|c|}{ Stratiform } \\
\hline & Light & Moderate & Heavy & Total & Light & Moderate & Heavy & Total \\
\hline$N_{w}(-)$ & 30.36 & 32.16 & 38.10 & 33.19 & 33.15 & 36.05 & 40.94 & 34.50 \\
\hline$D_{m}(\mathrm{~mm})$ & 1.61 & 1.85 & 1.89 & 1.77 & 1.28 & 1.45 & 1.45 & 1.34 \\
\hline РCT89 (K) & 268 & 258 & 245 & 259 & 265 & 255 & 251 & 261 \\
\hline STH $(\mathrm{km})$ & 7.7 & 8.9 & 10.2 & 8.8 & 7.1 & 7.9 & 8.0 & 7.3 \\
\hline
\end{tabular}



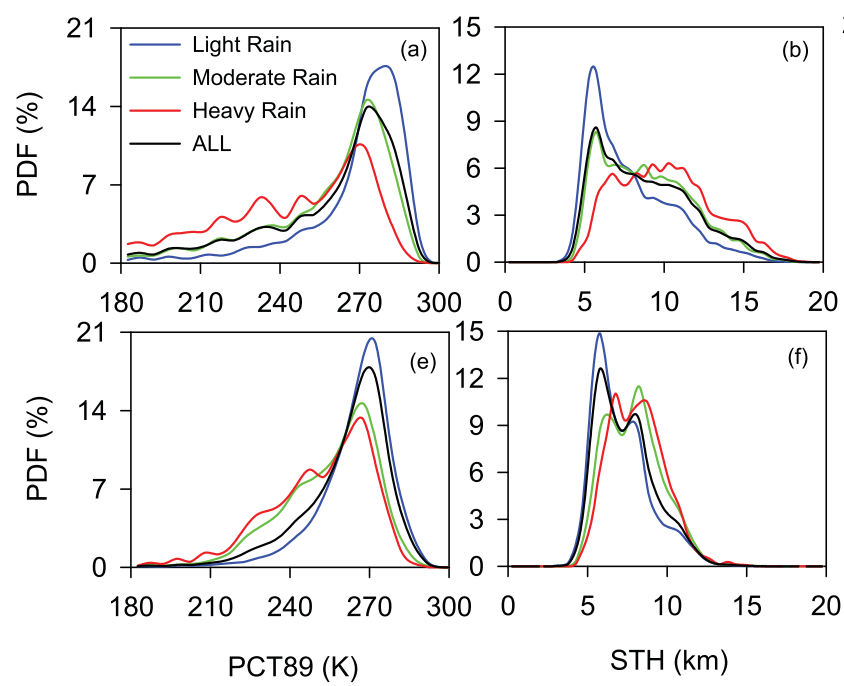

(b)

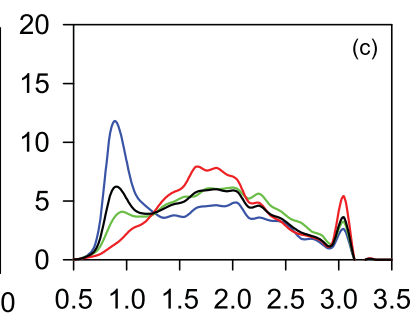

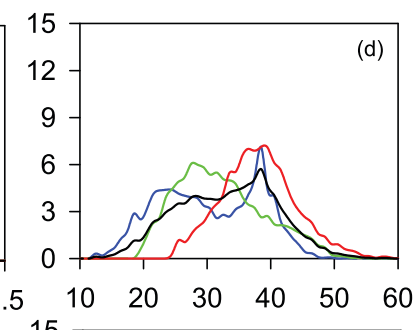
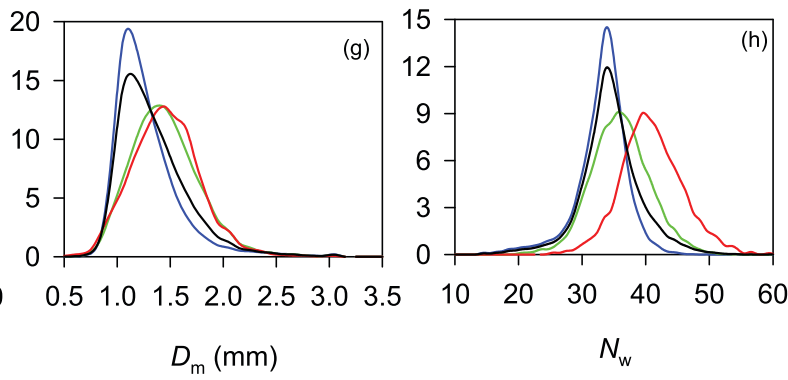

FIG. 3. The probability distribution functions (PDFs) of (a),(e) PCT89; (b),(f) STH; (c),(g) $D_{m}$; and (d),(h) $N_{w}$ at 2 km MSL in altitude for (top) convective and (bottom) stratiform precipitation at different rainfall intensities over the Yangtze-Huaihe River valley, China, during the summer monsoon seasons of 2014-19.

for light and moderate rain (Table 1). Fu and Liu (2003) also found that the PCT at $85 \mathrm{GHz}$ decreases sharply as the rainfall rate increases. For light, moderate, and heavy rain, the peak PDF values of PCT89 for convective precipitation are located at approximately 280, 275, and $270 \mathrm{~K}$, respectively. Although the mean PCT89 value for total convective precipitation (259 $\mathrm{K})$ over the Yangtze-Huaihe River valley is generally lower than that for total stratiform precipitation $(261 \mathrm{~K})$, the light and moderate rain of stratiform precipitation even have slightly lower PCT89 values than those of convective precipitation. It can be seen that for convective precipitation, the PDFs of the STHs for the light rain and moderate rain are unimodal (the peak is at $\sim 6 \mathrm{~km}$ ) (Fig. 3b), while those for the stratiform precipitation are bimodal with the peaks at $\sim 6$ and $\sim 8 \mathrm{~km}$. This result generally means for heavy rain, the convective clouds have higher echo tops than the stratiform clouds. But for light and moderate rain, there are great portions of convective clouds with low echo top, which means the ice-phase processes are not active within them and the PCT89 values are high (even higher than the stratiform precipitation).

The PDFs of $N_{w}$ and $D_{m}$ at $2 \mathrm{~km}$ in altitude above mean sea level exhibit significant differences between convective and stratiform precipitating clouds (Figs. 3c-g,d-h), even in their shape patterns. First, irrespective of the rainfall intensities, the sizes of raindrops for stratiform precipitation are more concentrated at relatively small values (unimodal), while those for convective precipitation have wider ranges (bimodal). Note that, the $D_{m}$ peak at $3 \mathrm{~mm}$ for convective precipitation is mainly because the maximum $D_{m}$ retrieved from DSD retrieval algorithm is set to $3 \mathrm{~mm}$ (Seto et al. 2016). It is also found that the $N_{w}$ values of convective precipitation show a wider span than stratiform precipitation, which ranges from 10 to $60 \mathrm{~dB} N_{w}$ for convective precipitation, and from 20 to $60 \mathrm{~dB} N_{w}$ for stratiform precipitation. The convective precipitation has more fractions of small $N_{w}$ values and large $D_{m}$ values. Second, the $N_{w}$ of light convective rain also has bimodal patterns with one peak ( $3 \%$ ) occurring when $N_{w}$ reaches $25 \mathrm{~dB} N_{w}$, and another peak when $N_{w}$ reaches 40 $\mathrm{dB} N_{w}$. Whereas for stratiform precipitation, the $N_{w}$ of light rain has a single peak and is concentrated mainly at moderate values $\left(35 \mathrm{~dB} N_{w}\right)$. For a given $\mathrm{RR}$ range, the $N_{w}$ values for stratiform precipitation have a narrower distribution than those for convective precipitation, with a larger mean $N_{w}$, as displayed in Table 1 . The $N_{w}$ of convective rain peaks at 30 $\mathrm{dB} N_{w}$ for moderate rain and at $40 \mathrm{~dB} N_{w}$ for heavy rain, while it peaks at 38 and $42 \mathrm{dBN}_{w}$ for stratiform precipitation, respectively. As given in Table 1 , the mean $D_{m}$ of convective precipitation is generally larger than that of stratiform precipitation. There are also notable fractions of small-sized hydrometeors $(\sim 0.7 \mathrm{~mm})$ for light and moderate convective rain, which are even smaller than those of stratiform precipitation. These convective pixels with $D_{m}<1 \mathrm{~mm}$ are mainly contributed by the convective precipitating clouds with $\mathrm{STH}<8 \mathrm{~km}$, which showing similar higher PCT89 values among different rainfall intensities indicative of smaller differences in ice particles within these clouds (not shown).

To further grasp the features of DSDs, the frequencies of $D_{m}$ and $N_{w}$ at $2 \mathrm{~km}$ in altitude are calculated for light, moderate, and heavy rain, as illustrated in Fig. 4. Irrespective of the rainfall intensity or rain type, the DSDs show high concentrations of small-sized rain hydrometeors and low concentrations of large-sized rain hydrometeors near the surface, which is in good agreement with previous studies (Chen et al. 2019; Huang and Chen 2019; Wang et al. 2016). For the overall DSD patterns of convective and stratiform precipitation (Figs. 4d,g), there are higher frequencies of large-sized hydrometeors $\left(D_{m}>2 \mathrm{~mm}\right)$ for convective precipitation than for stratiform precipitation. Similarly, for a given rainfall intensity range, the stratiform precipitation is characterized by smaller 

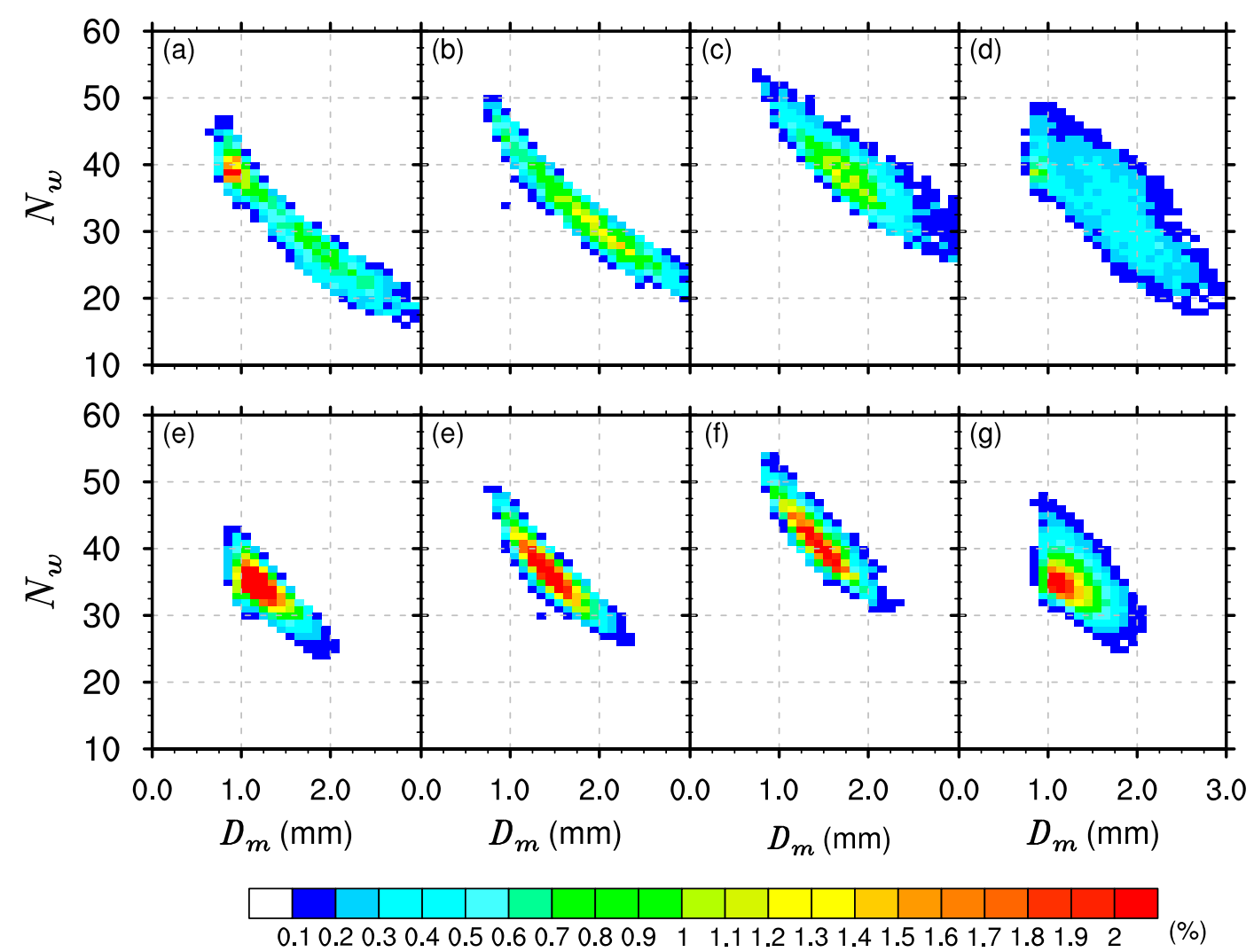

FIG. 4. The frequency pattern in two-dimensional space of near-surface $D_{m}$ and $N_{w}$ at $2 \mathrm{~km}$ MSL in altitude for (top) convective and (bottom) stratiform precipitation with rain rates (a),(e) lower than $2.5 \mathrm{~mm} \mathrm{~h}^{-1}$; (b),(f) $2.5-8 \mathrm{~mm} \mathrm{~h}^{-1}$; (c),(g) higher than $8 \mathrm{~mm} \mathrm{~h}^{-1}$; and (d),(h) all rain rates over the Yangtze-Huaihe River valley, China, during the summer monsoon seasons of 2014-19.

mean $D_{m}$ values and larger mean $N_{w}$ values (Table 1). For both convective and stratiform precipitation, precipitation with higher rainfall intensities has a positively skewed DSD with larger $N_{w}$ or larger $D_{m}$, suggesting the higher concentrations of larger-sized rain hydrometeors for clouds producing more intense rainfall.

\section{c. Vertical structures}

To reveal the variations in vertical structures of DSD parameters in terms of different rainfall intensities, the frequency patterns of $Z_{e}$ and $D_{m}$ in terms of altitude, known as contoured frequency patterns by altitude diagrams (CFADs; Yuter and Houze 1995), are calculated for convective and stratiform precipitation, as presented in Figs. 5 and 6 , respectively. The convective/stratiform CFADs represent the occurrences in each height-reflectivity (height- $D_{m}$ ) bin with respect to total convective/stratiform precipitating profiles.

According to the $0.02 \%$ contours, the vertical extents of convective precipitating clouds could reach more than $12 \mathrm{~km}$ in altitude (Fig. 5d), which are much higher than those of stratiform precipitation (Fig. 6d). Near the level of $\sim 4.5 \mathrm{~km}$ in altitude, the $Z_{e}$ of stratiform precipitation is the largest compared to those below or above this level. This well-known signature is bright band, which is caused by the melting of ice- phase particles. However, this phenomenon is not evident for convective precipitation. Above the melting layer, due to the combined effects of riming and aggregation of ice particles, the $Z_{e}$ and $D_{m}$ values of convective and stratiform precipitation increases as the altitudes decreases (Chen et al. 2019, 2016; Huang and Chen 2019). Below the melting layer, the $Z_{e}$ values of convective precipitation mostly equal to $40 \mathrm{~dB} Z$ (Fig. 5d), while only about $25 \mathrm{dBZ}$ for stratiform precipitation (Fig. 5h). Another notable difference is that there are two maximum frequency centers of $D_{m}(1.0$ and $2.0 \mathrm{~mm})$ for convective precipitation, but a unique maximum frequency center $(1.0 \mathrm{~mm})$ for stratiform precipitation. The maximum frequency center of $D_{m}$ at $1.0 \mathrm{~mm}$ for convective precipitation is produced mainly by the light convective precipitation, which is characterized by large fractions of small-sized hydrometeors (Figs. 4a and 5e).

Great discrepancies between CFADs at different rainfall intensities can be found for convective and stratiform precipitation (Figs. 5a-c,e-g and 6a-c,e-g). For convective precipitation, $Z_{e}$ and $D_{m}$ values are shifted to larger values throughout the column as the rainfall intensity increases. Below the melting layer, there are two maximum frequency centers for the light rain of convective precipitation, one at $1.0 \mathrm{~mm}$ and another at $2.0 \mathrm{~mm}$, which is different from the cases of heavy 

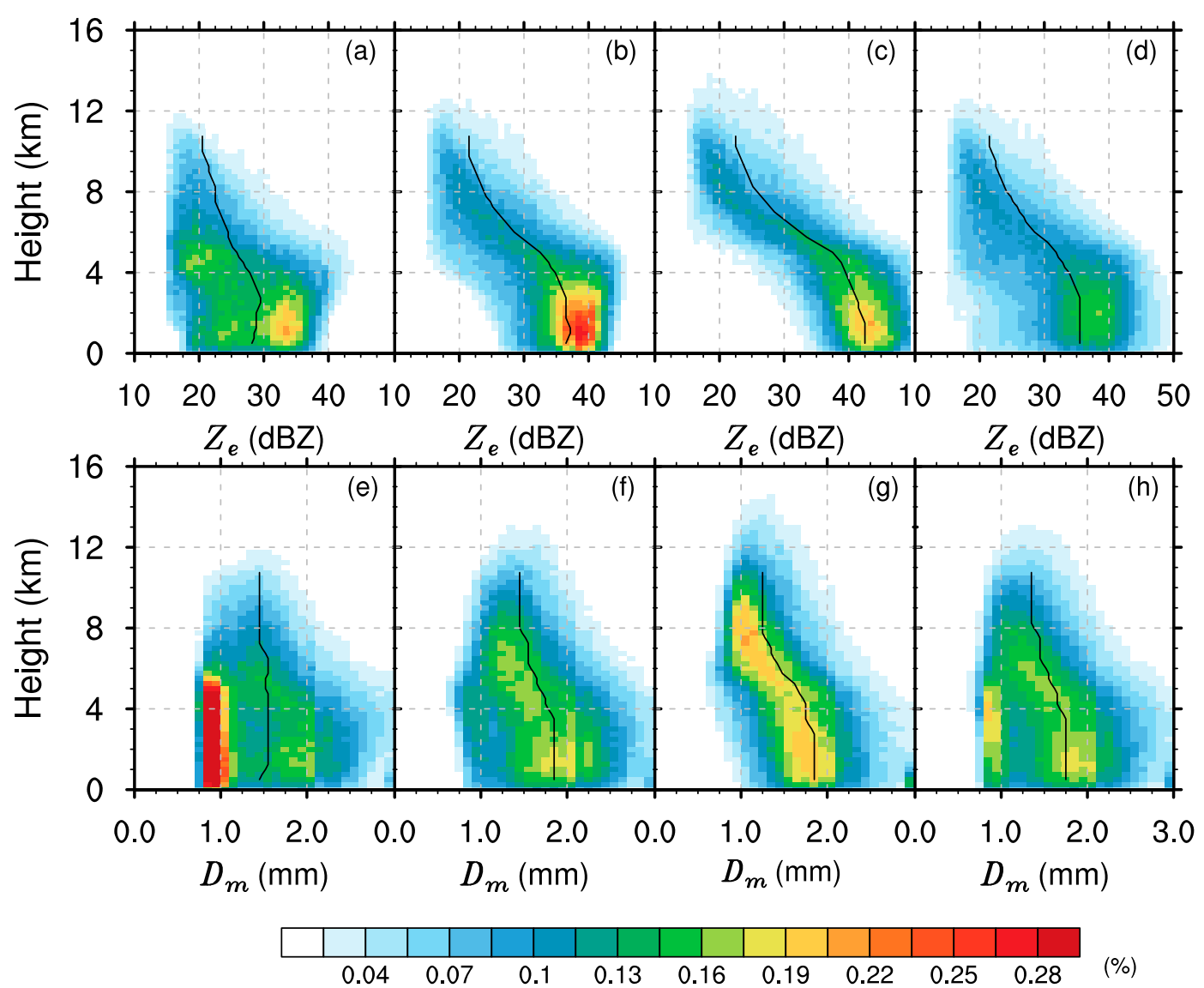

FIG. 5. The contoured frequency patterns by altitude diagrams (CFADs) of (top) $Z_{e}$ and (bottom) $D_{m}$ for convective precipitation at rain rates (a),(e) lower than $2.5 \mathrm{~mm} \mathrm{~h}^{-1}$; (b),(f) $2.5-8 \mathrm{~mm} \mathrm{~h}^{-1}$; (c), (g) greater than $8 \mathrm{~mm} \mathrm{~h}^{-1}$; and (d),(h) all rain rates over the Yangtze-Huaihe River valley, China, during the summer monsoon seasons of 2014-19. The solid black lines indicate the mediums of corresponding $Z_{e}$ and $D_{m}$ profiles.

and moderate rain. Additionally, the vertical slope of medium $Z_{e}$ below $4.5 \mathrm{~km}$ in altitude varies with the changes in rainfall intensity. For example, the $Z_{e}$ values of light rain decrease slightly when the rain hydrometeors fall to the ground, increase slightly for moderate rain, and increases more sharply for heavy rain. The differences may be attributed to different precipitation microphysical processes below the melting layer (Liu and Zipser 2013). As the rain hydrometeors fall to the ground, they tend to break up or evaporate for light rain. While for heavy precipitation, the accretion process or the coalescence between rain droplets may play an important role in the formation of heavy rainfall.

For stratiform precipitation, the vertical tendencies of $Z_{e}$ and $D_{m}$ profiles for different rainfall intensities are similar to those for convective precipitation. However, for a given rainfall intensity, apart from the obvious decrease in $Z_{e}$ and $D_{m}$ values for stratiform precipitation, there are also other dominating differences between convective and stratiform precipitation. First, the radar echo tops increase slightly with the increase in near-surface RR (Figs. 6a-c), but they increase more significantly for convective precipitation (Figs. 5a-c). These results probably imply that more vigorous convection is found for convective precipitation producing more intense rainfall, suggesting differences in ice-phase microphysical processes. Second, the $D_{m}$ of stratiform precipitation below the melting layer is mainly $1.0 \mathrm{~mm}$, which is different from the two maximum frequency centers for convective precipitation. Additionally, the increase in $Z_{e}$ values of heavy rain below the melting layer for stratiform precipitation is much higher than for convective precipitation. Previous studies have revealed that $Z_{e}$ increasing toward the surface can be attributed to collision-coalescence processes, whereas a downward decrease in $Z_{e}$ can be related to breakup and evaporation (Carr et al. 2017; Porcacchia et al. 2019). The sharper increases in $Z_{e}$ values of heavy rain for stratiform precipitation below the melting layer than that of convective precipitation therefore indicate more efficient growth by warm rain processes.

\section{d. DSD and PCT89}

The changes in brightness temperature at high $(89 \mathrm{GHz})$ microwave frequency depend on the scattering of ice particles within clouds (Liu and Fu 2001). The depression in brightness 

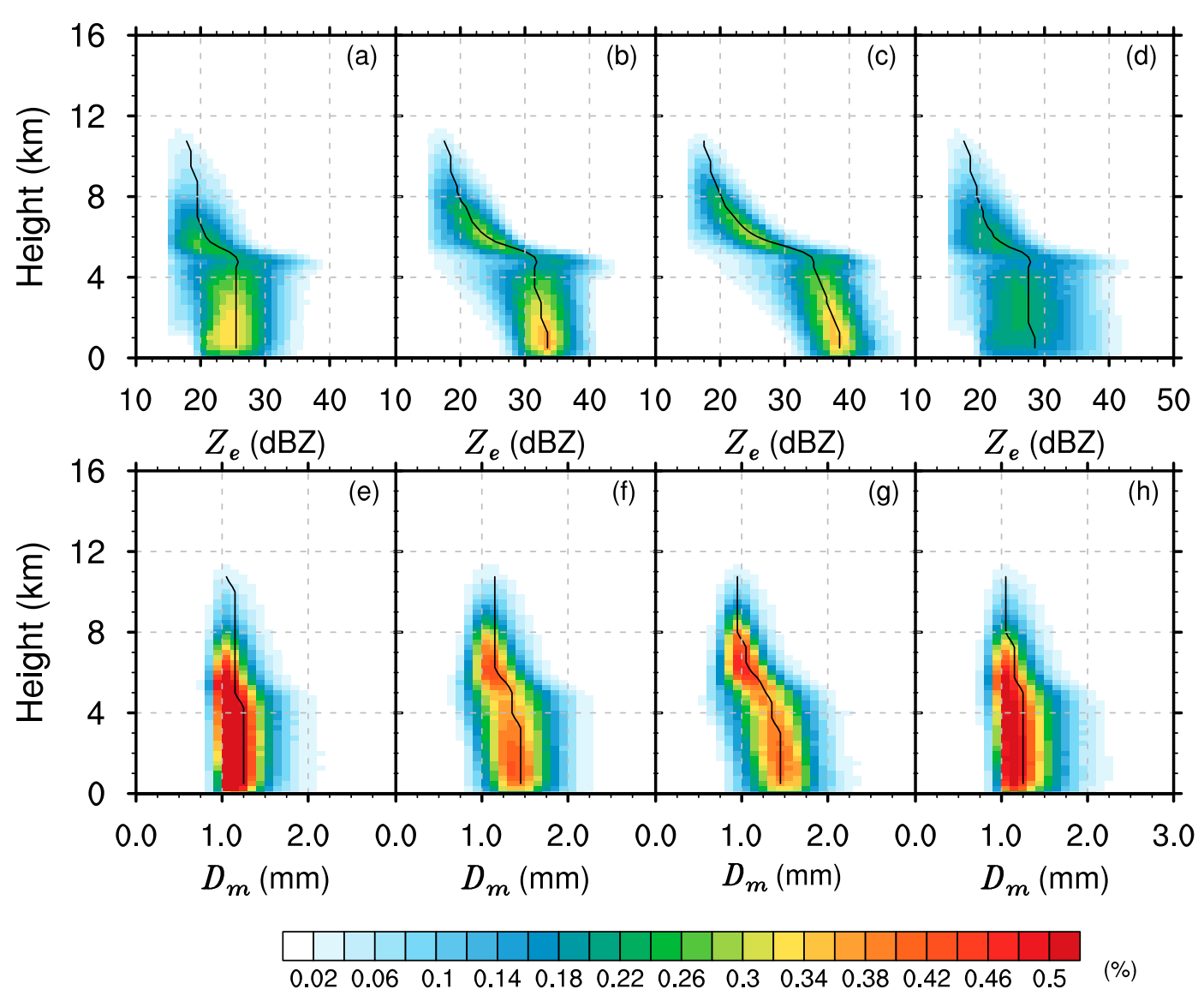

FIG. 6. As in Fig. 5, but for stratiform precipitation.

temperature from ice scattering, e.g., observed from Special Sensor Microwave Imager (SSM/I), TMI, and GMI, have been used to retrieve rainfall (Gopalan et al. 2010). Establishing the relationship between brightness temperature from satellite images and the DSDs may help diagnose the nearsurface microphysics and probably improve the rainfall retrieval algorithms. Thus, we calculated the mean relation between PCT89 and DSDs at $2 \mathrm{~km}$ in altitude for convective and stratiform precipitation, as presented in Fig. 7. The mean $N_{w}\left(D_{m}\right)$ is calculated as the ratio of the sum of $N_{w}\left(D_{m}\right)$ to the total samples in each 5-K bin range.

For total precipitation (black triangles), the $D_{m}$ and $N_{w}$ of stratiform precipitation show low sensitivity to PCT89 values when PCT89 are lower than $270 \mathrm{~K}$. The $D_{m}\left(N_{w}\right)$ increases (increases) slightly when PCT89 increases from 180 to $230 \mathrm{~K}$, and decrease slightly (stays almost constant) as PCT89 increases further to $270 \mathrm{~K}$. For convective precipitation, the $D_{m}\left(N_{w}\right)$ values increase (decrease) sharply with a decrease in PCT89. This indicates that the near-surface DSDs of stratiform precipitation vary little with the change in the total amounts of ice hydrometeors. In contrast, the ice-scattering signals in convective precipitation from microwave imagers have a high potential to inform the DSDs near the surface, i.e., with a decrease in PCT89 values, larger-sized hydrometeors are found for convective precipitation near the surface.
The low PCT89 values within convective precipitating clouds may indicate stronger updraft which facilitating the formation of graupel and hailstones at upper levels and hereafter could melt into larger rain drops during falling to the ground (Bringi et al. 2003). On the other hand, when the PCT 89 values are higher than $275 \mathrm{~K}$ (suggesting low ice-particle concentrations), both convective and stratiform precipitation show a sharp increase (decrease) in $D_{m}\left(N_{w}\right)$ with the increase in PCT89 values. This probably implies that warm rain processes (coalescence of water droplets) become more and more prevalent within these clouds when PCT89 gets larger.

As for different rainfall intensities, the $N_{w}$ of light, moderate, and heavy rain show similar trends to the total precipitation (black triangles) in terms of PCT89. For a given PCT89, the $N_{w}$ of light rain is the smallest, followed by the one of moderate rain, and then that of heavy rain. The most abrupt increases in $N_{w}$ values occur for heavy rain for both convective and stratiform precipitation (PCT89 < 270 K). From the perspective of $D_{m}$ values, for a given PCT89, the mean raindrop sizes are the smallest for light rain and largest for moderate rain. The $D_{m}$ of heavy rain mainly lies between those of light rain and moderate rain. These results show that for the same PCT89, heavy rain tends to have high concentrations of moderate raindrop sizes near the surface for convective and stratiform precipitation, which suggests that the growth of 

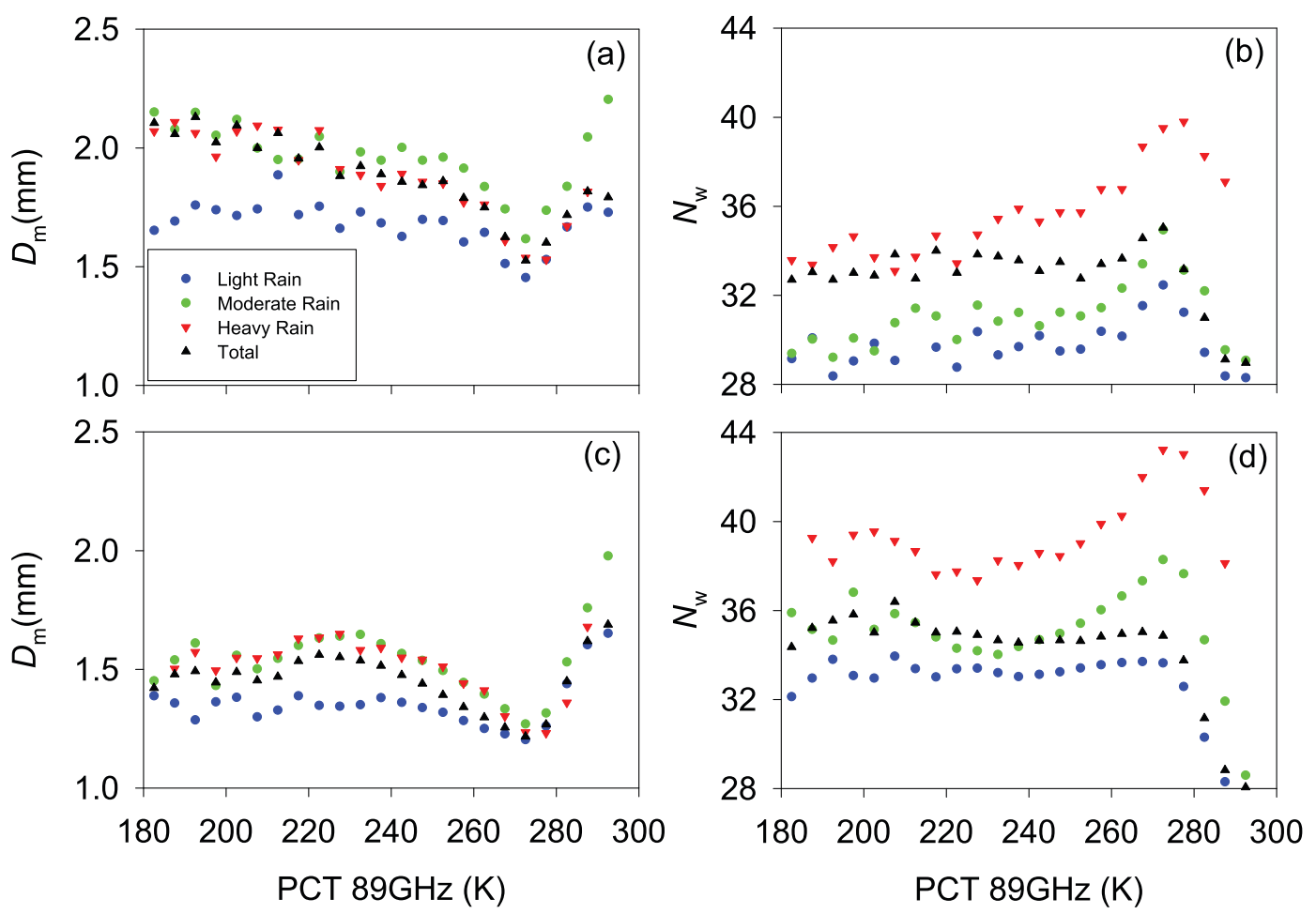

FIG. 7. The relationship between PCT89 and (a),(c) $D_{m}$ and (b),(d) $N_{w}$ at $2 \mathrm{~km}$ MSL in altitude for (top) convective and (bottom) stratiform precipitation at different rainfall intensities over the Yangtze-Huaihe River valley, China, during the summer monsoon seasons of 2014-19. The bin size of PCT89 is $5 \mathrm{~K}$.

heavy rainfall is mainly due to warm rain processes (autoconversion and accretion). Note that the $D_{m}$ of light rain for convective and stratiform precipitation show a similar change pattern to total precipitation when PCT89 is higher than 275 $\mathrm{K}$; but the $D_{m}$ values have different change patterns when PCT89 is lower than $275 \mathrm{~K}$, which stay almost constant for both convective and stratiform precipitation. This implies that the ice-phase particles process may have little bearing on the near-surface DSD estimations of light precipitation. Another dominant feature is that the change in $N_{w}$ values is more significant than change in $D_{m}$ values when the PCT89 values change, especially for heavy rain. Consistent with the near-surface DSDs shown in Fig. 4, for given rainfall intensities, the $N_{w}$ of stratiform precipitation are much larger than those of convective precipitation, while it is the opposite case for the $D_{m}$ values.

According to the PDFs of PCT89 in Fig. 3, the precipitation is classified into three categories to examine the linkages between ice-scattering signals and precipitation microphysics: namely, precipitation when PCT89 < 250 K, PCT89: 250-265 $\mathrm{K}$, and PCT89 $>265 \mathrm{~K}$. Figures 8 and 9 show the joint $D_{m}-N_{w}$ distribution at $2 \mathrm{~km}$ in altitude and the mean profiles of $Z_{e}$ and $D_{m}$ for convective and stratiform precipitation within different PCT89 ranges, respectively. In each individual PCT89 range, the convective precipitation has more fractions of large-sized raindrops relative to the stratiform precipitation. Meanwhile, $N_{w}$ values have much narrower distributions and higher mean values for stratiform precipitation, compared to convective precipitation. The mean $D_{m}$ and $\mathrm{Z}_{e}$ profiles of convective precipitation also exhibit much larger values than stratiform ones throughout the column (Fig. 9).

As shown in Fig. 8, the $D_{m}$ values for both convective and stratiform precipitation get larger if the PCT89 gets lower, with a largest mean $D_{m}$ at $2 \mathrm{~km}$ in altitude when PCT89< $250 \mathrm{~K}$. Meanwhile, we can find generally greater mean $D_{m}$ and $Z_{e}$ values for lower PCT89 values at almost all different altitudes as shown in Fig. 9. As pointed out earlier, the larger mean $D_{m}\left(Z_{e}\right)$ values above the melting level for low PCT89 values mainly results from the ice particle formed by the efficient rimming or aggregation process. Meanwhile, the $D_{m}$ $\left(Z_{e}\right)$ value for PCT89 $<250 \mathrm{~K}$ could be $0.4 \mathrm{~mm}(10 \mathrm{dBZ})$ greater than that for PCT $89<265 \mathrm{~K}$ for convective precipitation, while the difference is about $0.2 \mathrm{~mm}(6 \mathrm{dBZ})$ for stratiform precipitation. However, the changes in $D_{m}$ and $Z_{e}$ values below the melting level for different PCT89 intervals are generally similar and much less obvious than those above the melting level. The difference in the microphysical characteristics of near-surface precipitation for different PCT89 ranges are mainly attributed to the differences in their icephase growth. Therefore, the PCT 89 values can be used to diagnose the precipitation microphysics at lower altitudes.

\section{Summary and conclusions}

An understanding of the precipitation microphysics of convective and stratiform precipitation, including the linkage of 

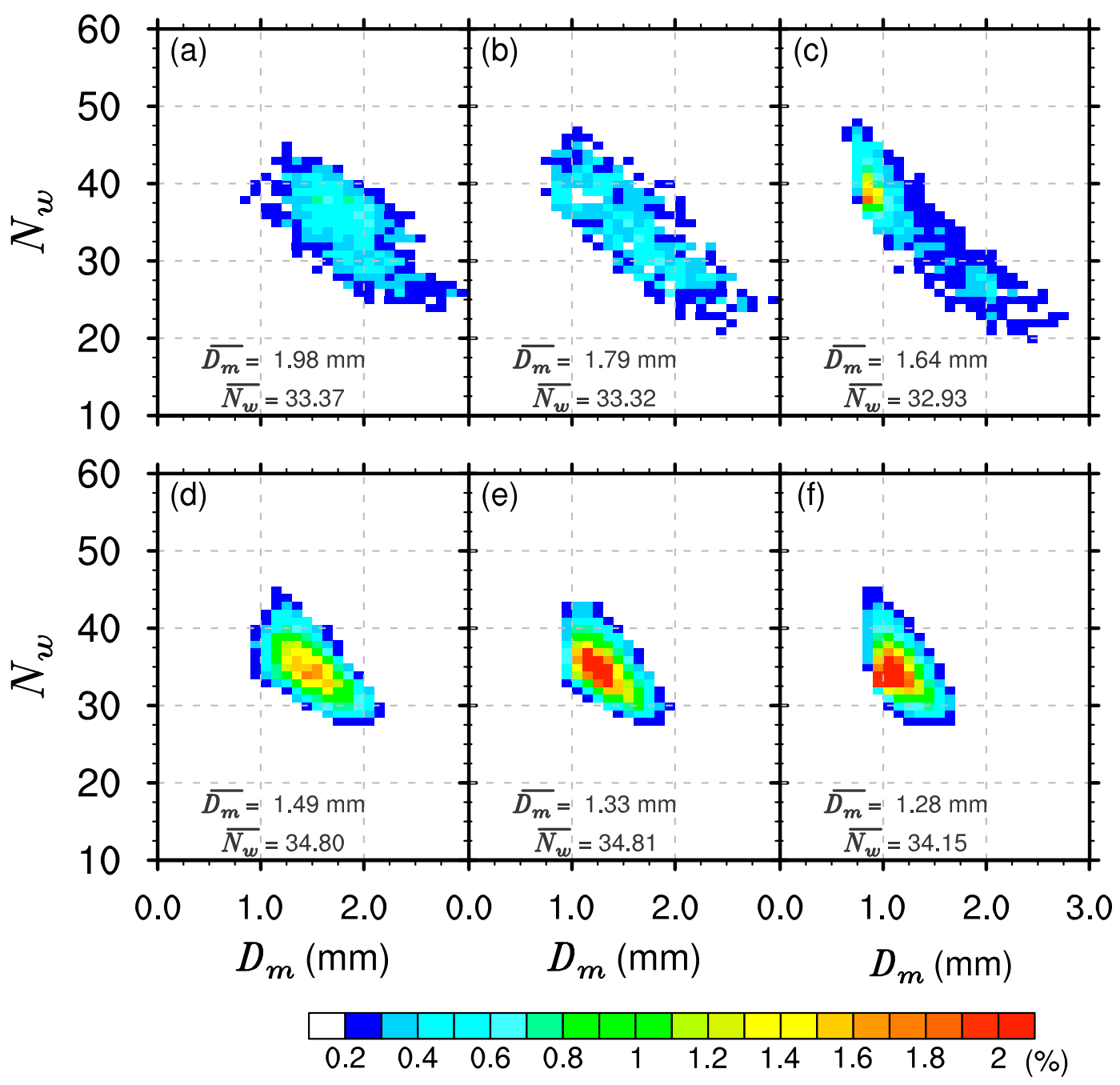

FIG. 8. The frequency pattern in two-dimensional space of near-surface $D_{m}$ and $N_{w}$ at $2 \mathrm{~km}$ MSL in altitude for (top) convective and (bottom) stratiform precipitation with PCT89 (a),(d) lower than $250 \mathrm{~K}$; (b), (e) 250-265 K; and (c),(f) higher than $265 \mathrm{~K}$ over the Yangtze-Huaihe River valley, China, during the summer monsoon seasons of 2014-19. The terms $\overline{D_{m}}$ and $\overline{N_{w}}$ indicate the mean $D_{m}$ and $N_{w}$ at $2 \mathrm{~km}$ in altitude, respectively.

microwave images and precipitation microphysics, is important for precipitation observation and forecasting over the Yangtze-Huaihe River valley. Six years of observations from DPR and GMI on board GPM have provided valuable datasets of quantitative analysis of precipitation microphysics over this region. Using the merged dataset of DPR and GMI, the precipitation microphysics of stratiform and convective precipitation over the Yangtze-Huaihe River valley have been examined in the present study, with special attention given to the differences in microphysical characteristics of light, moderate, and heavy rain.

Spatial patterns show that the heaviest convective RR is located mainly between the Huaihe and Yangtze Rivers, corresponding to smaller $D_{m}$ values, larger $N_{w}$ values, and lower PCT89 values (indicative of high concentrations of ice hydrometeors within clouds) than those over the surrounding regions. The high aerosol loadings and sufficient moisture may contribute to the high concentrations of small-sized rain hydrometeors near the surface over this region. The mean near-surface $D_{m}$ for convective precipitating clouds has a mode at $1.8 \mathrm{~mm}$, while it is concentrated at only $1.4 \mathrm{~mm}$ for stratiform precipitating clouds.

PCT89 is negatively correlated with rainfall intensity for both convective and stratiform precipitation. The precipitation producing the higher rain rate has the lower PCT89. The mean PCT89 values for total convective rain and heavy convective rain are lower than those for stratiform precipitation. Due to the existence of comparable fractions of convective and stratiform precipitating clouds with STH $<6 \mathrm{~km}$, the PCT89 values of light and moderate convective rain are even higher than the stratiform ones. The DSDs of convective and stratiform precipitation show high concentrations of smallsized rain hydrometeors and low concentrations of large-sized rain hydrometeors near the surface. As the rainfall intensity 

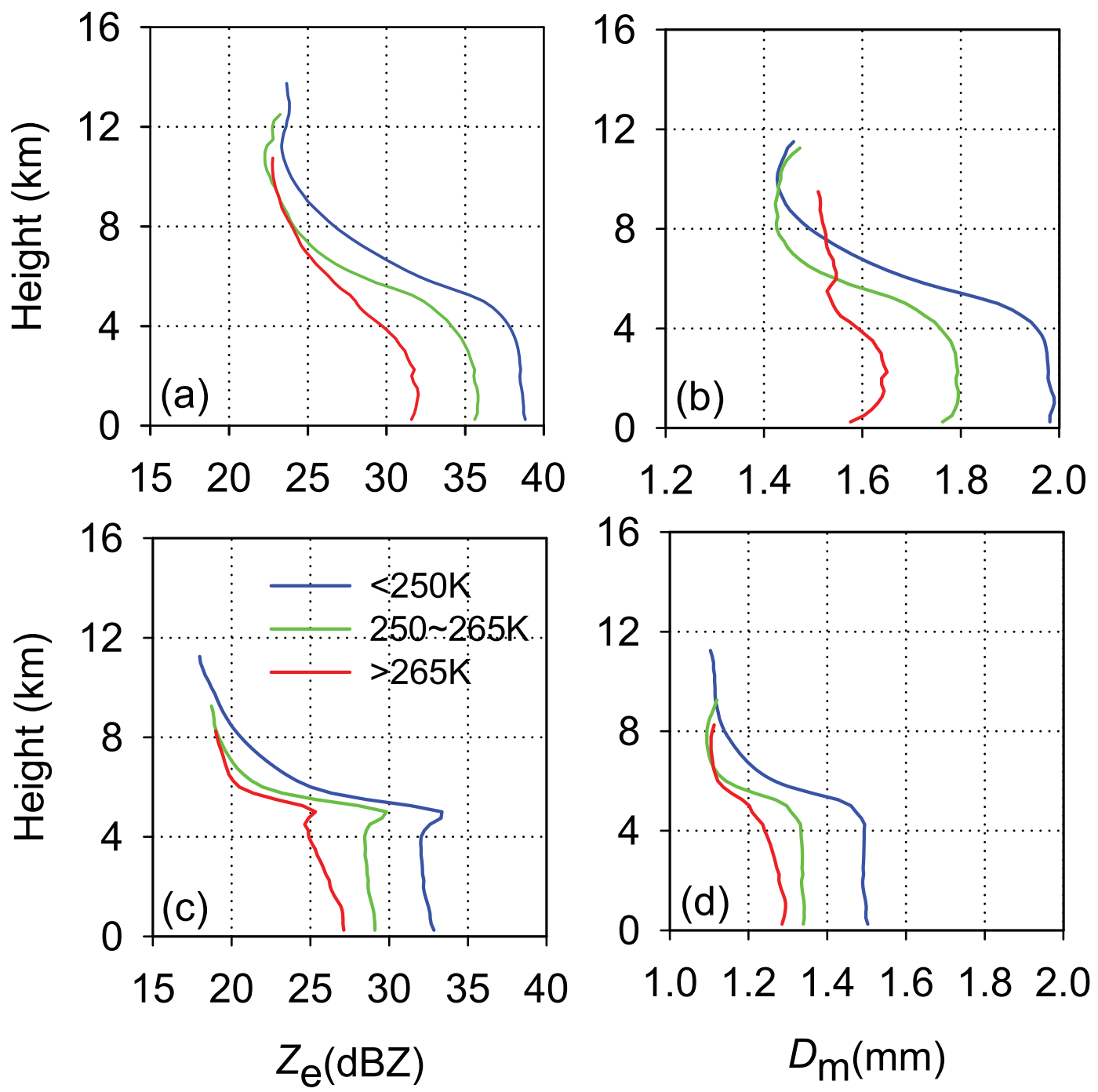

FIG. 9. The mean profiles of $Z_{e}$ and $D_{m}$ for (top) convective and (bottom) stratiform precipitation over the YangtzeHuaihe River valley, China, during the summer monsoon seasons of 2014-19. The blue, green, and red lines represent profiles for precipitation when PCT89 < 250 K, PCT89: 250-265 K, and PCT89 > 265 K, respectively.

increases, there are more DSDs with larger $N_{w}$ or larger $D_{m}$, associated with the increases in the average $D_{m}$ and $N_{w}$ values for both convective and stratiform precipitation, suggesting high concentrations of larger-sized rain hydrometeors for clouds producing more intense rainfall. For a given rainfall intensity, the stratiform precipitation is characterized by smaller mean $D_{m}$ values and larger mean $N_{w}$ values than convective precipitation. Note that there are higher frequencies of DSDs with small-sized hydrometeors $(\sim 0.7 \mathrm{~mm})$ for light and moderate convective rain precipitation those for stratiform precipitation, which is mainly contributed by the convective precipitating clouds with lower STH $(<8 \mathrm{~km})$ and higher PCT89 values.

The $Z_{e}$ and $D_{m}$ profiles are shifted to larger values throughout the column as the rainfall intensities increase for both convective and stratiform precipitation. Below $4.5 \mathrm{~km}$ in altitude above mean sea level, the vertical slope of medium $Z_{e}$ varies with the change in rainfall intensity, and decreases slightly when the rain hydrometeors fall to the ground, increases slightly for moderate rain, and increases more sharply for heavy rain. The increase in amplitude of $Z_{e}$ values for heavy rain below the melting layer for stratiform precipitation is much higher than for convective precipitation, probably due to more efficient growth by warm rain processes.

Compared to stratiform precipitation, the near-surface DSDs of convective precipitation show higher sensitivity to PCT89. Furthermore, relative to the $D_{m}$ values, the PCT89 are more sensitive to the $N_{w}$ values near the surface. In a comparison between different rainfall intensities, the PCT89 show the lowest sensitivity to the near-surface DSDs of light precipitation. With a decrease in PCT89 values (ranging between 180 and $270 \mathrm{~K}$ ), lower concentrations of larger-sized hydrometeors are found for convective precipitation near the surface. As the PCT89 becomes warmer than $270 \mathrm{~K}$, larger-sized 
rain hydrometeors are found as PCT89 increases to larger values, which probably implies warm rain processes (coalescence of water droplets).

The mean profiles of $D_{m}\left(Z_{e}\right)$ vary with the change in PCT89 values. Generally greater mean $D_{m}$ and $Z_{e}$ values for lower PCT89 values are found at almost all different altitudes. The most evident differences lie below $4 \mathrm{~km}$ in altitude, where the differences in mean $D_{m}\left(Z_{e}\right)$ values could reach about $0.4 \mathrm{~mm}$ (10 dBZ) for convective precipitation and $0.2 \mathrm{~mm}(6 \mathrm{dBZ})$ for stratiform precipitation (for precipitation when PCT89 < $250 \mathrm{~K}$ or PCT $89>265 \mathrm{~K}$ ). The changes in $D_{m}$ and $Z_{e}$ values below the melting level for different PCT89 intervals are generally similar to those above the melting level, which indicate that the differences in the microphysical characteristics of nearsurface precipitation for different PCT89 ranges are mainly attributed to the differences in their ice-phase growth.

It is important to know that the uncertainties of DSDs retrievals resulted from the measurement errors, attenuation correction, and the assumptions of DSD model, mixing model, and melting process may lead to some uncertainties in the analysis of precipitation microphysical characteristics (Seto and Iguchi 2011). Although, the results from a large amount of accumulated data may partially cancel out the effect of the retrieval uncertainty, improvements in attenuation correction and DSD retrieval algorithms are still needed for future investigations on precipitation microphysics using GPM data. In this study, the possible reasons for the regional differences of DSDs over different parts of Yangtze-Huaihe River valley have been analyzed. However, more case studies and model studies are still needed in the future to find the dynamical and physical reasons. Due to temporal and spatial variations of DSDs, the light, moderate, and heavy rainfall events over different parts of the world are worthy to be further studied.

Acknowledgments. This work has been jointly supported by National Key Research and Development Project of China (2019YFC1510303), National Natural Science Foundation of China (Grant 41805023), Basic Research Fund of CAMS (2020R002), and the innovation team construction plan by Anhui Meteorological Bureau. The authors declare no conflicts of interest.

Data availability statement. The GPM DPR and GMI data provided by NASA Goddard Space Flight Center's Mesoscale Atmospheric Processes Laboratory and Precipitation Processing System (PPS) can be downloaded from https:// pmm.nasa.gov/dataaccess/downloads/gpm. The daily ERAInterim can be downloaded from https://apps.ecmwf.int/ datasets/data/interim-full-daily.

\section{REFERENCES}

Awaka, J., T. Iguchi, H. Kumagai, and K. Okamoto, 1997: Rain type classification algorithm for TRMM precipitation radar. 1997 IEEE Int. Geoscience and Remote Sensing Symp., Singapore, IEEE, 1633-1635, https://doi.org/10.1109/IGARSS.1997. 608993.
—- M. Le, V. Chandrasekar, N. Yoshida, T. Higashiuwatoko, T. Kubota, and T. Iguchi, 2016: Rain type classification algorithm module for GPM Dual-Frequency Precipitation Radar. J. Atmos. Oceanic Technol., 33, 1887-1898, https://doi.org/10. 1175/JTECH-D-16-0016.1.

Bringi, V. N., V. Chandrasekar, J. Hubbert, E. Gorgucci, W. L. Randeu, and M. Schoenhuber, 2003: Raindrop size distribution in different climatic regimes from disdrometer and dual-polarized radar analysis. J. Atmos. Sci., 60, 354-365, https://oi.org/ 10.1175/1520-0469(2003)060<0354:RSDIDC > 2.0.CO;2.

Carr, N., P. E. Kirstetter, J. J. Gourley, and Y. Hong, 2017: Polarimetric signatures of midlatitude warm-rain precipitation events. J. Appl. Meteor. Climatol., 56, 697-711, https://doi.org/ 10.1175/JAMC-D-16-0164.1.

Cecil, D. J., 2009: Passive microwave brightness temperatures as proxies for hailstorms. J. Appl. Meteor. Climatol., 48, 12811286, https://doi.org/10.1175/2009JAMC2125.1.

—_, and E. J. Zipser, 2002: Reflectivity, ice scattering, and lightning characteristics of hurricane eyewalls and rainbands. Part II: Intercomparison of observations. Mon. Wea. Rev., 130, 785-801, https://doi.org/10.1175/1520-0493(2002)130<0785: RISALC $>2.0 . \mathrm{CO} ; 2$.

Chakravarty, K., and P. E. Raj, 2013: Raindrop size distributions and their association with characteristics of clouds and precipitation during monsoon and post-monsoon periods over a tropical Indian station. Atmos. Res., 124, 181-189, https://doi. org/10.1016/j.atmosres.2013.01.005.

Chen, B., Z. Hu, L. Liu, and G. Zhang, 2017: Raindrop size distribution measurements at $4,500 \mathrm{~m}$ on the Tibetan Plateau during TIPEX-III. J. Geophys. Res. Atmos., 122, 11092-11106, https://doi.org/10.1002/2017JD027233.

Chen, F., and Y. Fu, 2015: Contribution of tropical cyclone rainfall at categories to total precipitation over the Western North Pacific from 1998 to 2007. Sci. China Earth Sci., 58, 2015-2025, https://doi.org/10.1007/s11430-015-5103-9.

,,-- P. Liu, and Y. Yang, 2016: Seasonal variability of storm top altitudes in the tropics and subtropics observed by TRMM PR. Atmos. Res., 169, 113-126, https://doi.org/10. 1016/j.atmosres.2015.09.017.

,$--\frac{1}{-}$, and Y. Yang, 2019: Regional variability of precipitation in tropical cyclones over the Western North Pacific revealed by the GPM dual-frequency precipitation radar and microwave imager. J. Geophys. Res. Atmos., 124, 1128111296, https://doi.org/10.1029/2019JD031075.

Deo, A., and K. J. E. Walsh, 2016: Contrasting tropical cyclone and non-tropical cyclone related rainfall drop size distribution at Darwin, Australia. Atmos. Res., 181, 81-94, https://doi.org/ 10.1016/j.atmosres.2016.06.015.

Ding, Y., 1994: The Summer Monsoon in East Asia. Monsoons over China, Springer Netherlands, 1-90.

— Z Z. Wang, and Y. Sun, 2008: Inter-decadal variation of the summer precipitation in East China and its association with decreasing Asian summer monsoon. Part I: Observed evidences. Int. J. Climatol., 28, 1139-1161, https://doi.org/10.1002/joc. 1615.

- , Y. Liu, and Z.-Z. Hu, 2021: The record-breaking meiyu in 2020 and associated atmospheric circulation and tropical SST anomalies. Adv. Atmos. Sci., 38, 1980-1993, https://doi.org/10. 1007/s00376-021-0361-2.

Draper, D. W., D. A. Newell, F. J. Wentz, S. Krimchansky, and G. M. Skofronick-Jackson, 2015: The Global Precipitation Measurement (GPM) Microwave Imager (GMI): Instrument overview and early on-orbit performance. IEEE J. Sel. Top. 
Appl. Earth Obs. Remote Sens., 8, 3452-3462, https://doi.org/ 10.1109/JSTARS.2015.2403303.

Fu, Y., and G. Liu, 2003: Precipitation characteristics in mid-latitude East Asia as observed by TRMM PR and TMI. $J$. Meteor. Soc. Japan, 81, 1353-1369, https://doi.org/10.2151/ jmsj.81.1353.

— , and Coauthors, 2016: Recent trends of summer convective and stratiform precipitation in mid-eastern China. Sci. Rep., 6, 33044, https://doi.org/10.1038/srep33044.

Gopalan, K., N.-Y. Wang, R. Ferraro, and C. Liu, 2010: Status of the TRMM 2A12 land precipitation algorithm. J. Atmos. Oceanic Technol., 27, 1343-1354, https://doi.org/10.1175/ 2010JTECHA1454.1.

He, J., J. Zheng, Z. Zeng, Y. Che, M. Zheng, and J. Li, 2021: A comparative study on the vertical structures and microphysical properties of stratiform precipitation over South China and the Tibetan Plateau. Remote Sens., 13, 2897, https://doi. org/10.3390/rs13152897.

Homeyer, C. R., and M. R. Kumjian, 2015: Microphysical characteristics of overshooting convection from polarimetric radar observations. J. Atmos. Sci., 72, 870-891, https://doi.org/10. 1175/JAS-D-13-0388.1.

Hou, A. Y., and Coauthors, 2014: The Global Precipitation Measurement mission. Bull. Amer. Meteor. Soc., 95, 701-722, https://doi.org/10.1175/BAMS-D-13-00164.1.

Huang, H., and F. Chen, 2019: Precipitation microphysics of tropical cyclones over the western North Pacific based on GPM DPR observations: A preliminary analysis. J. Geophys. Res. Atmos., 124, 3124-3142, https://doi.org/10.1029/2018JD029454. -, and Coauthors, 2018: Quantitative precipitation estimation with operational polarimetric radar measurements in southern China: A differential phase-based variational approach. J. Atmos. Oceanic Technol., 35, 1253-1271, https://doi.org/10. 1175/JTECH-D-17-0142.1.

—, K. Zhao, G. Zhang, D. Hu, and Z. Yang, 2020a: Optimized raindrop size distribution retrieval and quantitative rainfall estimation from polarimetric radar. J. Hydrol., 580, 124248, https://doi.org/10.1016/j.jhydrol.2019.124248.

,-- , H. Chen, D. Hu, P. Fu, Q. Lin, and Z. Yang, 2020b: Improved attenuation-based radar precipitation estimation considering the azimuthal variabilities of microphysical properties. J. Hydrometeor., 21, 1605-1620, https://doi.org/10.1175/ JHM-D-19-0265.1.

,-- , P. Fu, H. Chen, G. Chen, and Y. Zhang, 2021: Validation of precipitation measurements from the dual-frequency precipitation radar onboard the GPM core observatory using a polarimetric radar in South China. IEEE Trans. Geosci. Remote Sens., 1-16, https://doi.org/10.1109/TGRS.2021. 3118601 , in press.

Iguchi, T., R. Oki, E. Smith, and Y. Furuhama, 2002: Global precipitation measurement program and the development of dual-frequency precipitation radar. J. Commun. Res. Lab., 48, 37-45.

—, and Coauthors, 2018: GPM/DPR level-2. Algorithm Theoretical Basis Doc., 127 pp., https:/gpm.nasa.gov/sites/default/ files/2019-05/ATBD_DPR_201811_with_Appendix3b.pdf.

Jun, A., M. Le, V. Chandrasekar, N. Yoshida, T. Higashiuwatoko, T. Kubota, and T. Iguchi, 2016: Rain type classification algorithm module for GPM dual-frequency precipitation radar. $J$. Atmos. Oceanic Technol., 33, 1887-1898, https://doi.org/10. 1175/JTECH-D-16-0016.1.

Kumjian, M. R., A. P. Khain, N. Benmoshe, E. Ilotoviz, A. V. Ryzhkov, and V. T. J. Phillips, 2014: The anatomy and physics of $Z_{\mathrm{DR}}$ columns: Investigating a polarimetric radar signature with a spectral bin microphysical model. J. Appl. Meteor. Climatol., 53, 1820-1843, https://doi.org/10.1175/ JAMC-D-13-0354.1.

Le, M., and V. Chandresekar, 2012: A potential DSD retrieval process for Dual-Frequency Precipitation Radar (DPR) on board GPM. Proc. SPIE, 8523, 852307, https://doi.org/10. 1117/12.977597.

Liu, G., and Y. Fu, 2001: The characteristics of tropical precipitation profiles as inferred from satellite radar measurements. $J$. Meteor. Soc. Japan, 79, 131-143, https://doi.org/10.2151/jmsj. 79.131.

Liu, C., and E. J. Zipser, 2013: Why does radar reflectivity tend to increase downward toward the ocean surface, but decrease downward toward the land surface? J. Geophys. Res. Atmos., 118, 135-148, https://doi.org/10.1029/2012JD018134.

,$- \ldots$, and S. W. Nesbitt, 2007: Global distribution of tropical deep convection: Different perspectives from TRMM infrared and radar data. J. Climate, 20, 489-503, https://doi.org/10. 1175/JCLI4023.1.

$\longrightarrow,-$ D. J. Cecil, S. W. Nesbitt, and S. Sherwood, 2008: A cloud and precipitation feature database from nine years of TRMM observations. J. Appl. Meteor. Climatol., 47, 27122728, https://doi.org/10.1175/2008JAMC1890.1.

Liu, J., Y. Zheng, Z. Li, and M. Cribb, 2011: Analysis of cloud condensation nuclei properties at a polluted site in southeastern China during the AMF-China Campaign. J. Geophys. Res., 116, D00K35, https://doi.org/10.1029/2011JD016395.

Porcacchia, L., P.-E. Kirstetter, V. Maggioni, and S. Tanelli, 2019: Investigating the GPM dual-frequency precipitation radar signatures of low-level precipitation enhancement. Quart. J. Roy. Meteor. Soc., 145, 3161-3174, https://doi.org/10.1002/qj. 3611.

Radhakrishna, B., and T. Narayana Rao, 2010: Differences in cyclonic raindrop size distribution from southwest to northeast monsoon season and from that of noncyclonic rain. J. Geophys. Res., 115, D16205, https://doi.org/10.1029/ 2009JD013355.

_ , S. Satheesh, T. Narayana Rao, K. Saikranthi, and K. Sunilkumar, 2016: Assessment of DSDs of GPM-DPR with ground-based disdrometer at seasonal scale over Gadanki, India. J. Geophys. Res. Atmos., 121, 11 792-11802, https://doi. org/10.1002/2015JD024628.

Rosenfeld, D., and C. W. Ulbrich, 2003: Cloud microphysical properties, processes, and rainfall estimation opportunities. Radar and Atmospheric Science: A Collection of Essays in Honor of David Atlas, R. M. Wakimoto and R. Srivastava, Eds., Amer. Meteor. Soc., 237-258.

Seela, B. K., J. Janapati, P.-L. Lin, K. K. Reddy, R. Shirooka, and P. K. Wang, 2017: A comparison study of summer season raindrop size distribution between Palau and Taiwan, two islands in Western Pacific. J. Geophys. Res. Atmos., 122, 11787-11 805, https://doi.org/10.1002/2017JD026816.

,,,--- P. K. Wang, and M.-T. Lee, 2018: Raindrop size distribution characteristics of summer and winter season rainfall over North Taiwan. J. Geophys. Res. Atmos., 123, 11602 11624, https://doi.org/10.1029/2018JD028307.

Seto, S., and T. Iguchi, 2011: Applicability of the iterative backward retrieval method for the GPM dual-frequency precipitation radar. IEEE Trans. Geosci. Remote Sens., 49, 1827-1838, https://doi.org/10.1109/TGRS.2010.2102766.

_ - T. Shimozuma, T. Iguchi, and T. Kozu, 2016: Spatial and temporal variations of mass-weighted mean diameter estimated 
by GPM/DPR. 2016 IEEE Int. Geoscience and Remote Sensing Symp., Beijing, China, IEEE, 3938-3940, https://doi.org/10.1109/ IGARSS.2016.7730023.

Smith, E. A., and Coauthors, 2007: International Global Precipitation Measurement (GPM) program and mission: An overview. Measuring Precipitation from Space, Springer, 611-653.

Spencer, R. W., H. M. Goodman, and R. E. Hood, 1989: Precipitation retrieval over land and ocean with the SSM/I: Identification and characteristics of the scattering signal. J. Atmos. Oceanic Technol., 6, 254-273, https://doi.org/10.1175/15200426(1989)006<0254:PROLAO > 2.0.CO;2.

Steiner, M., R. A. Houze, and S. E. Yuter, 1995: Climatological characterization of three-dimensional storm structure from operational radar and rain gauge data. J. Appl. Meteor. Climatol., 34, 1978-2007, https://doi.org/10.1175/1520-0450(1995) 034<1978:CCOTDS > 2.0.CO;2.

Sun, Y., and Coauthors, 2020: Vertical structures of typical meiyu precipitation events retrieved from GPM-DPR. J. Geophys. Res. Atmos., 125, e2019JD031466, https://doi.org/10.1029/ 2019JD031466.

Tang, Q., H. Xiao, C. Guo, and L. Feng, 2014: Characteristics of the raindrop size distributions and their retrieved polarimetric radar parameters in northern and southern China. Atmos. Res., 135-136, 59-75, https://doi.org/10.1016/j.atmosres.2013. 08.003.

Wang, H., F. Kong, N. Wu, H. Lan, and J. Yin, 2019: An investigation into microphysical structure of a squall line in South China observed with a polarimetric radar and a disdrometer. Atmos. Res., 226, 171-180, https://doi.org/10.1016/j.atmosres. 2019.04.009.

Wang, M., K. Zhao, M. Xue, G. Zhang, S. Liu, L. Wen, and G. Chen, 2016: Precipitation microphysics characteristics of a Typhoon Matmo (2014) rainband after landfall over eastern China based on polarimetric radar observations. J. Geophys. Res. Atmos., 121, 12415-12 433, https://doi.org/10. 1002/2016JD025307.
Wen, L., K. Zhao, G. Zhang, M. Xue, B. Zhou, S. Liu, and X. Chen, 2016: Statistical characteristics of raindrop size distributions observed in East China during the Asian summer monsoon season using 2-D video disdrometer and Micro Rain Radar data. J. Geophys. Res. Atmos., 121, 2265-2282, https://doi.org/10.1002/2015JD024160.

,-- , M. Wang, and G. Zhang, 2019: Seasonal variations of observed raindrop size distribution in East China. Adv. Atmos. Sci., 36, 346-362, https://doi.org/10.1007/s00376-0188107-5.

Wood, R., T. L. Kubar, and D. L. Hartmann, 2009: Understanding the importance of microphysics and macrophysics for warm rain in marine low clouds. Part II: Heuristic models of rain formation. J. Atmos. Sci., 66, 2973-2990, https://doi.org/10. 1175/2009JAS3072.1.

Yang, Y., H. Wang, F. Chen, X. Zheng, Y. Fu, and S. Zhou, 2019: TRMM-based optical and microphysical features of precipitating clouds in summer over the Yangtze-Huaihe River Valley, China. Pure Appl. Geophys., 176, 357-370, https://doi.org/ 10.1007/s00024-018-1940-8.

Yu, F., Z. Chen, X. Ren, and G. Yang, 2009: Analysis of historical floods on the Yangtze River, China: Characteristics and explanations. Geomorphology, 113, 210-216, https://doi.org/ 10.1016/j.geomorph.2009.03.008.

Yuter, S. E., and R. A. Houze, 1995: Three-dimensional kinematic and microphysical evolution of Florida Cumulonimbus. Part II: Frequency distributions of vertical velocity, reflectivity, and differential reflectivity. Mon. Wea. Rev., 123, 1941-1963, https://doi.org/10.1175/1520-0493(1995)123<1941:TDKAME $>2$. $0 . \mathrm{CO} ; 2$.

Zeng, Q., and Coauthors, 2019: Microphysical characteristics of precipitation during pre-monsoon, monsoon, and post-monsoon periods over the South China Sea. Adv. Atmos. Sci., 36, 1103-1120, https://doi.org/10.1007/s00376-019-8225-8. 